\title{
Saúde Mental, Direitos, Cidadania: o escritório de advocacia como agência para inclusão social*
}

MENTAL HEALTH, RIGHTS AND CITIZENSHIP:

THE LAW OFFICE AS AN AGENT FOR SOCIAL INCLUSION

\author{
SALUD MENTAL, DERECHOS, CIUDADANÍA: LAOFICINADEABOGACÍA \\ COMO AGENCIA PARA LA INCLUSIÓN SOCIAL
}

Taia Duarte Mota ${ }^{1}$, Sônia Barros ${ }^{2}$

\section{RESUMO}

A Reforma Psiquiátrica discute questões relacionadas à inclusão dos loucos no mundo, tomando como projeto principal a construção da cidadania, ante a reconstrução dos Direitos, reconhecendo que os doentes mentais se encontram em condição de exclusão, pela própria condição, pelo trabalho e fragilidade social. 0 Centro de Atenção Psicossocial Professor Luiz da Rocha Cerqueira pretende interferir na condição de excluído do doente mental, por meio de projetos, entre eles o Escritório, que é um dispositivo de agenciamento social, promotor de alianças, que proporciona a possibilidade de os indivíduos atingirem patamares cada vez mais elevados de gerenciamento de suas vidas. Este estudo teve como objetivos principais caracterizar o usuário do Escritório e verificar a importância dessa intervenção para eles. Foram realizadas entrevistas com quatro usuários, os quais avaliaram o serviço, compreendendo que ele facilita a inserção no mundo dos direitose, portanto, pode ser considerado como importante tecnologia em saúde mental.

\section{DESCRITORES}

Saúde mental.

Desinstitucionalização.

Direitos humanos.

\begin{abstract}
The Psychiatric Reform discusses issues related to the inclusion of individuals that suffer from mental disorders, having as its main project the construction of citizenship through the reconstruction of their rights and recognizing that mentally ill individuals are in a condition of exclusion because of their very condition, the work and the social fragility. The Centro de Atenção Psicossocial Prof. Luiz da Rocha Cerqueira intends to interfere in the exclusion condition of mentally ill individuals through a number of projects, among them its Law Office, a social service agent that, by promoting alliances, offers to its users the possibility to reach higher and higher levels of management of their lives. The purpose of this study was to characterize the users of the Law Office and verify the importance of such intervention to them. Four users were interviewed and were asked to evaluate the service. They showed understanding of the fact that the service makes their insertion into the world of rights easier and therefore may be considered an important technology in mental health.
\end{abstract}

\section{KEY WORDS}

Mental health.

Deinstitutionalization.

Human rights.

\section{RESUMEN}

La Reforma Psiquiátrica discute cuestiones relacionadas a la inclusión de los locos en el mundo, tomando como proyecto principal la construcción de la ciudadanía, por medio de la reconstrucción de los Derechos, reconociendo que los enfermos mentales se encuentran en condición de exclusión, por la propia condición, por el trabajo y fragilidad social. El Centro de Atención Psicosocial Profesor Luiz da Rocha Cerqueira pretende interferir en la condición de excluido del enfermo mental, por medio de proyectos, entre ellos la Oficina, que es un dispositivo de agenciamento social, promotor de alianzas, que proporciona la posibilidad de que los individuos alcancen niveles cada vez más elevados de gerenciamiento de sus vidas. Este estudio tuvo como objetivos principales caracterizar al usuario de la Oficina y verificar la importancia que tiene para ellos esa intervención. Se llevaron a cabo entrevistas con cuatro usuarios, los cuales evaluaron el servicio, comprendiendo que él facilita la inserción en el mundo de los derechos y, por tanto, puede ser considerado como una importante tecnología en salud mental.

\section{DESCRIPTORES}

Salud mental.

Desinstitucionalización.

Derechos humanos.

\footnotetext{
* Extraído da pesquisa de iniciação científica financiada pelo PIBIC/CNPq, durante a Graduação em Enfermagem, Escola de Enfermagem, Universidade de São Paulo (EEUSP). ${ }^{1}$ Mestranda na área de concentração Materno-Infantil e Psiquiátrica pela Escola de Enfermagem da USP. São Paulo, SP, Brasil. taiaduarte@pop.com.br ${ }^{2}$ Professora Doutora Livre Docente do Departamento de Enfermagem Materno-Infantil e Psiquiátrica da Escola de Enfermagem da Universidade de São Paulo. São Paulo, SP, Brasil. sobarros@usp.br
} 


\section{INTRODUÇÃO}

0 Processo de Reforma Psiquiátrica no Brasil tem tomado como tema a condição de exclusão, na qual os doentes mentais se encontram. A Reforma discutiu questões relacionadas à inserção dos loucos no mundo, tomando como tarefa principal a cidadania ${ }^{(1)}$ entendida como projeto aberto às singularidades e especificidades de diversas formas de expressão da condição humana ${ }^{(1)}$.

A exclusão dos portadores de transtornos psíquicos severos tem sua origem relacionada à psiquiatria moderna, pós-revolução industrial, que associou o distúrbio psíquico à inadaptabilidade do ser humano ao processo produtivo.

A história da psiquiatria brasileira, em consonância com a mundial, escreveu-se através da reclusão do doente mental em locais onde reinava a violência, a despersonalização do indivíduo e a intolerância, transformando-o em uma coisa e, como tal, sem necessidades individuais ou direitos, portanto, este deixava de ser entendido como cidadão(2).

Desse modo, a exclusão não se esgota no mercado de trabalho, mas ganha significação tanto mais drástica no processo de destruição de valores integrativos tradicionais, atingindo a precariedade marcada pela não pertença e impotência ${ }^{(3)}$.

Nesse sentido, a exclusão social está ligada à solidão, à desagregação social, aos impactos das condições econômicas e a crise do liame social. Relegando ao sujeito com transtorno mental grave, um processo duplo de exclusão do emprego e de fragilização social(4).

Com a dificuldade de se incorporar no processo produtivo, na medida em que foi sendo suprimido desse universo, o doente mental tornou-se incapaz de reproduzir sua existência. Dessa forma, passou a ter positividade apenas na dimensão de doente, de suporte da doença. Para esses sujeitos que não encontraram lugar na sociedade e que não encontraram pares para diminuir o sofrimento, algumas vezes, encontram no corpo doente um modo de ter a cidadania reconhecida ${ }^{(5)}$.

Pensar a inclusão social do doente mental torna-se mais complexo, na medida em que, esse sujeito vive um conflito crônico de não inserção pela própria condição de saúde e pelo mundo do trabalho. Podemos pensar na reabilitação desses indivíduos, o que significa ajudá-los a ter mais autonomia, mais independência e poder criar normas para dirigir suas próprias vidas.

0 Centro de Atenção Psicossocial Professor Luiz da Rocha Cerqueira (CAPS Itapeva), serviço de atenção à saúde mental, pertencente à rede pública de serviços de saúde, que se destina ao atendimento de pacientes com transtornos mentais graves, em parceria com o Programa de
Integração Docente Assistencial em Saúde M ental - PIDA, (executado através de um convênio entre a Universidade de São Paulo e a Secretaria de Estado da Saúde do Estado de São Paulo), pretendeu interferir na condição de excluído, das pessoas com transtornos mentais, buscando sua inclusão no jogo social, proporcionando-lhes a possibilidade de atingir patamares cada vez mais elevados de gerenciamento de suas vidas e aumentado sua capacidade de escolha.

O Escritório opera com os seguintes marcos teóricos, do ponto de vista clínico(6):

a) Concepção crítica do processo saúde doença mental;

b) Os princípios para proteção de pessoas acometidas por transtorno mental, aprovado pela assembléia Geral da ONU em 17 de dezembro de 1991;

\section{c) Os pressupostos da Reforma Psiquiátrica Brasileira}

E do ponto de vista do ordenamento jurídico, operam $\mathrm{com}^{(6)}$ :

a) A carta M agna, Constituição Federal, de 05 de outubro de 1988;

b) 0 Código Civil Brasileiro, 01 de janeiro de 1916 e o decreto no. 54.559 de 03/07/34;

c) Código Penal Brasileiro;

d) Código de saúde no estado de São Paulo. Lei estadual complementar no. 791 de 09 de março de 1995.

Além disso, na atualidade, a lei 10.216, de 6 de abril de 2001, que dispõe sobre a proteção e os direitos das pessoas portadoras de transtornos mentais e redireciona o modelo assistencial em saúde mental, regulamentando, entre outros, o direito à internação somente mediante laudo médico circunstanciado.

É nessa perspectiva que o PIDA/CAPS atende 0 sujeito social e sua vocação cidadã, por meio do Escritório de Advocacia para Direitos, Saúde Mental \& Cidadania.

Esse escritório tem funcionado como um dispositivo de agenciamento social, que promove parcerias e alianças entre as instituições prestadoras de assistência a Saúde Mental e os movimentos organizados como a Ordem dos Advogados do Brasil, a Comissão dos direitos humanos e o Ministério Público ${ }^{(7)}$.

A compreensão da complexidade do processo exclusão/inclusão motivou o desenvolvimento do estudo que tem por finalidade avaliar a possibilidade de expansão das atividades do Escritório, na tentativa de diminuir o fosso que separa os excluídos/doentes, dos incluídos ${ }^{(1)}$. Para 0 alcance de tal finalidade são previstos vários objetivos, dentre eles: verificar resultados das intervenções realizadas pelo Escritório. Resolvemos então, complementarmente ao citado Projeto, desenvolver este estudo com os seguintes objetivos: 
- Caracterizar o usuário que procura o Escritório de Advocacia para Direitos, Saúde M ental \& Cidadania;

- Verificar a importância que o Escritório tem, na opinião de seus usuários, em suas vidas;

- Identificar se do ponto de vista do usuário, suas necessidades foram atendidas.

\section{MÉTODO}

Trata-se de uma pesquisa qualitativa, pois se preocupa com os significados da realidade que não podem ser simplesmente quantificados. É um estudo descritivo, que se caracteriza pela interrogação direta dos indivíduos sobre os significados que um determinado assunto produz em suas vidas ${ }^{(8)}$.

Esta pesquisa foi realizada no Centro de Atenção Psicossocial Luis da Rocha Cerqueira, após aprovação do projeto pelo Comitê de Ética e Pesquisa da Escola de Enfermagem da USP (Processo n. 335/2003). Dentre seus projetos de atendimento, encontra-se o Escritório de Advocacia para Direito, Saúde Mental \& Cidadania.

De acordo com o trabalho apresentado no estudo temos o seguinte quadro de atendimentos do Escritório, distribuído ao longo dos anos (Quadro 1).

Quadro 1 - Atendimentos do Escritório - São Paulo 1997-2001

\begin{tabular}{|c|c|}
\hline Ano & Matriculados \\
\hline 1997 & 05 \\
\hline 1998 & 25 \\
\hline 1999 & 83 \\
\hline 2000 & 56 \\
\hline 2001 & 43 \\
\hline Total & 212 \\
\hline
\end{tabular}

Os sujeitos da pesquisa foram os usuários do CAPS, que procuraram o Escritório no período de janeiro a junho de 2003, e preencheram os seguintes pré-requisitos: estar em tratamento nesse serviço de saúde no período eleito para o levantamento dos dados, ter procurado 0 Escritório nesse mesmo período, ter condições pessoais de participar da entrevista. Foram selecionados seis usuários que preencheram os pré-requisitos, dos quais dois não foi possível ter contato para realização da entrevista.

Inicialmente foi realizada uma reunião com a equipe do Escritório, para apresentação da pesquisadora e do projeto.

Imediatamente após, passou-se para a pesquisa no arquivo, através das fichas de atendimento do Escritório para levantamento do número de pessoas atendidas no primeiro semestre de 2003.
Após consentimento informado e assinatura do termo de consentimento livre esclarecido por parte dos sujeitos foram realizadas entrevistas semi-estruturadas, que foram gravadas e transcritas pela pesquisadora.

Na primeira fase organiza-se 0 material a ser analisado. Nesse momento, de acordo com os objetivos e questões de estudo, construímos as frases temáticas que posteriormente constituiriam as categorias. Foi necessário realizar leitura exaustiva do material coletado, para poder apreender as idéias principais e a mensagem que transmite. As falas foram separadas em frases temáticas e agrupadas, conforme seu sentido, em duas categorias.

A segunda fase constitui-se da análise e interpretação dos dados colhidos a partir das leituras realizadas anteriormente, nessa fase devemos tentar desvendar o conteúdo subjacente ao que está sendo manifesto( ${ }^{(9)}$. Para tanto elegemos como método a análise de conteúdo, pois, através dela podemos desco brir o que está por trás do que foi manifestado, podendo ir além das aparências do que está sendo dito( ${ }^{(9)}$.

\section{RESULTADOS E ANÁLISE}

\section{Caracterização da população}

O Número total de atendimentos realizados no primeiro semestre de 2003 no Escritório foi de 23, dos quais seis são usuários do CAPS Itapeva. Conforme os pré-requisitos citados anteriormente, participaram desta pesquisa quatro sujeitos, dos quais, dois homens e duas mulheres, estando em faixa etária compreendida entre trinta e um e cinqüenta anos.

Atualmente, estima-se que cerca de 450 milhões de pessoas sofram de transtornos mentais, ou de problemas psicossociais como aqueles relacionados ao abuso do álcool ou outras drogas, das quais a depressão é segunda principal causa da carga mundial de doenças; 70 milhões de pessoas são dependentes de álcool e 24 milhões esquizofrênicos, entre outros ${ }^{(10)}$.

Não há prevalência entre sexos, exceto para as depressões. No entanto, para a esquizofrenia o início da doença é mais precoce em homens do que em mulheres. Segundo estudos, a doença mental é um sofrimento principalmente de adultos e adultos jovens ${ }^{(11)}$.

Com relação ao diagnóstico atual dos sujeitos da pesquisa temos dois F31. 0-transtorno afetivo bipolar, um F20. 0-esquizofrenia paranóide e um F23. 2 -psicótico agudo de tipo esquizofrênico ${ }^{(12)}$.

Cerca de $10 \%$ dos adultos do mundo sofrem ou sofrerão algum tipo de transtorno mental no decorrer de suas vidas. Para a esquizofrenia a prevalência é de 1 a $1,5 \%$ e para os transtornos de humor a prevalência é $1 \%$ e tem inicio mais precoce em relação a maioria, a qual se dá 
entre 5,6 até os 50 anos de idade, no entanto a média é nos 30 anos(11).

Quanto ao estado civil encontramos apenas um divorciado e o restante solteiro. Três dos sujeitos da pesquisa moram sozinhos: um mora na rua, um em pensão e um em albergue da prefeitura. 0 único que mora com a mãe, vive em casa própria.

Em relação ao grau de escolaridade, apenas um possui curso superior incompleto, dois estudaram até 0 ensino médio e um o ensino fundamental. Dois não possuíam profissão, um é contador e um produtor musical.

Trata-se de um grupo de pessoas com grande vulnerabilidade social:

A clientela que nos procura, por suas características peculiares: baixo grau de escolaridade, formação profissional precária, inserção preconceituosa no imaginário coletivo, habilidade intelectual restringida pelo uso de psicofármacos, relação familiar permeada pela desconfiança com relação a sua capacidade produtiva, condição sócio-econômica dependente, enfrenta situações dramáticas relacionadas à sua condição de ser humano constitutivamente fragilizado por um Intenso Transtorno ${ }^{(7)}$.

\section{0 direito do usuário de Serviços de Saúde Mental}

A construção da cidadania no Brasil tem enfrentado uma série de dificuldades. $E$, no que se refere ao doente mental o processo de aquisição de direitos será sempre mais obstaculizado que a cidadania do conjunto da população brasileira(13).

A partir de 1987, quando o M ovimento de Trabalhadores em Saúde Mental assumiu seu caráter de movimento social ${ }^{(14)}$, e passou a ocupar-se dos direitos do doente mental, é que essa questão apareceu como modalidade de cuidado em saúde mental. Desse momento em diante passou-se a entender que a participação social do usuário é um meio importante para a reabilitação psicossocial e para um bom prognóstico da doença.

Para tanto, é necessária uma rede de amparo ao louco, sua família e as pessoas que entrarão em contato com ele, além dos espaços para o suporte durante a crise e a garantia das condições mínimas de sobrevivência aos que não tem nenhum outro centro de apoio(10).

A reestruturação da Saúde M ental torna-se necessária e, com ela a construção de um novo saber técnico-científi$\mathrm{co}$, que enfoque a garantia dos direitos do cidadão em sofrimento mental e sua família e a constituição de uma rede de amparo social, que garanta condições mínimas de sobrevivência, tais como, moradia, alimentação, acesso ao mercado de trabalho.

Um primeiro aspecto levantado pelos sujeitos desta pesquisa, abordado de forma positiva, é o fato de o Escritório ser um meio de garantir a moradia.
Quem me ajuda a arrumar pensão é aqui (o Escritório) (Ea3).

Já consegui da outra vez uma vaga no albergue pra morar. Morar em albergue é melhor que morar na rua (Eb9).

Um aspecto importante da reabilitação psicossocial é o doente mental ter garantido um local para morar/viver, onde possa sentir-se seguro e confortável nesse ambiente e que, além disso, tenha o direito de sair, caso não se sinta bem-vindo, mas com um outro local garantido para morar ${ }^{(15)}$.

A necessidade de ter um ambiente acolhedor, também, para os momentos de conflito familiar tornou-se mais importante com a diminuição dos leitos psiquiátricos.

As falas abaixo mostram quão difíceis são as relações familiares e demonstram a dificuldade do sistema de saúde em amparar os indivíduos que não têm um lugar na família:

Quando a mãe fala que você é louco todo mundo acredita (Ec7).

Ela (a mãe) não me deixa voltar pra casa (Ec4).

Meus pais morreram. (mora em albergue desde então) (Eb3).

A construção do processo de desenvolvimento do indivíduo é marcada pelas relações familiares e sociais, mas podemos inferir que no doente mental estão comprometidas. Além das relações, também é fundamental para 0 processo de desenvolvimento, a possibilidade de garantir meios de produzir e trocar mercadorias, não só como atividade laboral, mas, também, como atividade de lazer.

No entanto, esse sujeito tem sua inclusão no mercado de trabalho, muito restrita, além de não ter seus direitos previdenciários garantidos. Muitas vezes, a dificuldade de se inserir no mercado é devida ao comprometimento da própria doença e do tratamento farmacológico.

Fui procurar o escritório para entrar com pedido de $\operatorname{LOAS}^{(a)}(\mathrm{Ea1})$.

(procurar o serviço do escritório) Para pedir aposentadoria (Ed1).

A dificuldade de ter seu direito social atendido é percebida por muitos dos atores deste estudo, como vemos nas falas abaixo:

O pedido (LOAS) foi negado (Ea8).

Eles querem que você esteja deprimente que nem possa usar o dinheiro (Ed2).

Ainda não consegui nada (Ed8).

(a) Lei Orgânica da Assistência Social (LOAS). Lei n. 8.742, de 7 de dezembro de 1993. Dispõe sobre a assistência social. Provê os mínimos salários para manutenção das necessidades básicas, à pessoa portadora de deficiência e ao idoso que comprovem não ter meios de manter a própria manutenção ou de tê-la provida por sua família. 
A possibilidade de se pensar na saúde mental por um outro paradigma, o da construção da cidadania, aumenta a possibilidade de intervenções, as quais ultrapassam a medicação e a psicoterapia.

A valorização do campo social aumenta a eficácia da intervenção e diminui o processo de cronificação, além de citar a pobreza das relações sociais, também, como agente facilitador das crises $^{(14)}$.

A maior dificuldade em relação aos cuidados na saúde mental é o grande desamparo social. A falta de intervenção do Estado, para garantir algumas necessidades básicas, causa grande impacto no doente mental, em sua doença e em sua relação familiar.

Não tenho um real pra nada (Eb5).

(morar na rua) não tem a menor segurança (Eb11).

A instabilidade gerada pela inconsistência das políticas de amparo social, que não garante, de fato, questões como moradia e alimentação, acarretam em mal-estar, tanto individual, como coletivo, o que dificulta as relações sociais e o desenvolvimento humano ${ }^{(16)}$.

As frases temáticas abaixo ilustram a angústia do indivíduo que não tem nada garantido.

Fico dependendo dos outros pra tudo (Eb6).

Não posso ter nada que gost (Eb13).

Só como quando tem comida, como aqui no CAPS (Eb7).

Assim:

A cidadania é um fenômeno multideterminado e, para debruçarmos sobre ele é necessário um empreendimento interdisciplinar; buscar a construção das diferenças e das desigualdades na história é buscar seus pressupostos básicos nas teorias de conhecimento de outrora, os quais continuam tendo eco nas representações atuais ${ }^{(7)}$.

\section{Avaliação do atendimento no Escritório}

0 Escritório através de atendimentos nas áreas Civis, Criminais, Trabalhistas e Previdenciária, busca assegurar o exercício dos direitos sociais e individuais dos usuários e familiares do PIDA/CAPS e, também dos usuários da Rede Pública e Privada de assistência, objetivando desarticular as associações: doença mental $X$ periculosidade; vigência de crise $X$ incapacidade permanente; autonomia relativa $X$ improdutividade ${ }^{(7)}$.

O Escritório tem como um de seus pressupostos a intervenção nas subjetividades das pessoas, onde o campo clínico e jurídico se interseccionam ${ }^{(6)}$.

É a partir das alianças com outras instituições e serviços, que o Escritório promove a inclusão do doente mental, pois possibilita sua participação do jogo social e tenta garantir um mínimo de acesso aos bens de consumo. Sendo que os próprios usuários identificam esse serviço dessa forma, conforme a fala abaixo:
Não tenho nenhum dinheiro (Eb2).

Mesmo tendo essa população tais dificuldades pessoais e sociais, conseguem, de maneira muito habilidosa, avaliar 0 atendimento, o serviço e sua equipe, pensando nos problemas que estão relacionados estritamente ao Escritório, como nos ilustra a fala abaixo:

Ele podia tentar (refere-se ao profissional do Escritório que se negou a pedir a cópia de seu prontuário do hospital que esteve internado) (Ec11).

Aqui (no Escritório) é muito bem atendido, aqui é bem orientado, eles orientam bem (Ea5).

0 atendimento realizado no Escritório é bem avaliado, pois é percebido como um espaço de reivindicação para quem está desamparado socialmente. Tal como as falas abaixo ilustram:

(o Escritório) é um suporte, uma infra-estrutura (Ea11).

Pelo menos é um jeito pras pessoas daqui (CAPS Itapeva) terem um lugar (Escritório) pra tentar os direitos (Ed9).

Outra característica apontada como positiva é o fato do Serviço ter um bom padrão de orientação; há um consenso entre a equipe do Escritório em orientar detalhadamente, tanto usuário, quanto familiar, quanto os passos a serem seguidos e o tempo de espera. Assim nos mostram os sujeitos abaixo:

Sempre orienta bem (Ea6).

Disse (um membro da equipe do Escritório) que tenho que ter paciência, que as coisas são demoradas mesmo (Ed5).

O Escritório iniciou seus trabalhos em julho de 1997 com o intuito de garantir os direitos individuais, familiares e sociais dos usuários dos serviços de saúde. Essa modalidade de intervenção clínica trabalha a partir da ampliação da compreensão do objeto de trabalho da saúde, tal concepção faz uso da história de vida do individuo e não apenas dos sinais e sintomas da doença, portanto entende-se doença como um processo e não como falta de saúde.

Tal entendimento obriga-nos a ampliar o repertório de intervenções, para muito além das competências técnicas, uma vez que entendemos o usuário dos serviços de saúde mental, como um indivíduo que, bem como a população, possui necessidades de ganhar dinheiro, viver dignamente, ter acesso aos bens de consumo, ter uma vida afetiva e amorosa estável além do tratamento no seu sentido mais amplo(6).

Conforme já referido, o doente mental tem seu poder contratual reduzido, pelas próprias dificuldades que a doença e o tratamento impõem. É nesse cenário que 0 Escritório aparece, como mediador entre as necessidades do individuo, suas limitações e a garantia de seus direitos como cidadão.

A seguir temos a fala de um usuário que procurou 0 Escritório para pedir a interdição de sua mãe, pois acreditava ser esta a única forma de conseguir voltar para casa. 
(Pedir a interdição da mãe) Para poder voltar par casa. Não é a primeira vez que tenho que fazer isso (Ec3).

Nesse caso a atuação clínica não passa por medicação, ou tecnologias muito avançadas, mas pela mediação entre a família e o paciente ou, caso tal mediação seja impossível, pela construção, com esse indivíduo, de uma nova forma de viver que seja menos sofrida para ambos os sujeitos da intervenção.

Segundo um estudo(17), resta-nos os o desafio de encontrar formas de escutar as pessoas, pois é na escuta que está o desvendar dos mistérios do sofrimento, e só dessa forma poderemos saber onde e como intervir.

\section{O Escritório atua através da:}

Intervenção micro-social, na subjetividade da pessoa, onde os campos clínico e jurídico se interseccionam numa função mediadora com o outro social, entendido como todo campo que possibilita ou inviabiliza o uso das prerrogativas dos direitos individuais e coletivos: órgãos burocráticos, sistema de transporte, sistema previdenciário, aparelho jurídico etc(7).

Por conseguinte, temos que desenvolver uma tecnologia de cuidados que considere um compromisso ético de acolher e cuidar de pessoas culturalmente desinseridas, socialmente abominadas ${ }^{(17)}$.

\section{CONSIDERAÇÕES FINAIS}

O Escritório de advocacia para direitos, saúde mental e cidadania pode ser considerado como agência para inclusão social de pessoas portadoras de transtornos men-

\section{REFERÊNCIAS}

1. Barros S, Oliveira MAF, Aranha e Silva AL. Inclusão social de pessoas com transtornos mentais severos e persistentes. Cad IPUB. 2001;6(19):171-81.

2. Silva ATMC, Barros S, Oliveira MAF. Políticas de saúde e de saúde mental no Brasil: a exclusão/inclusão social como intenção e gesto. Rev Esc Enferm USP. 2002;36 (1):4-9.

3. Demo P. Charme da exclusão social. São Paulo: Autores Associados; 1998.

4. Paugam S. O enfraquecimento e a ruptura os vínculos sociais: uma dimensão essencial do processo de des-qualificação social. In: Sawaia B, organizadora. As artimanhas da exclusão: análise psicossocial e ética da desigualdade social. Petrópolis: Vozes; 2001. p. 67-86.

5. Carreteiro TC. "A Doença como projeto" - uma contribuição à análise da dialética inclusão/exclusão. In: Sawaia $\mathrm{B}$, organizadora. As artimanhas da exclusão: análise psicossocial e ética da desigualdade social. Petrópolis: Vozes; 2001. p. 87-95. tais severos, para os indivíduos que participaram deste trabalho. Ele funcionou como um intermediário entre as necessidades individuais desses sujeitos e as ações necessárias para atendê-las.

Pudemos perceber que na opinião dos sujeitos desta pesquisa, suas necessidades foram parcialmente atendidas. As necessidades individuais que não geram ônus para o Estado foram atendidas: local para morar, pedido de divórcio, entre outras. No entanto as necessidades macroestruturais, relacionadas aos direitos do cidadão, que tem como principal representante o pedido de aposentadoria revelou grande dificuldade de serem atendidas.

Mesmo assim, o serviço foi reconhecido como tecnologia importante para o tratamento destes indivíduos. Acreditamos que tal avaliação deve-se ao fato dele ter como característica, boa comunicação com seus freqüentadores, além de explicar e orientar cada etapa dos processos, tal como foi citado pelos próprios sujeitos.

Entendemos e defendemos a assistência à saúde mental como um instrumento para a reconstrução do poder contratual do indivíduo em sofrimento mental, o que consiste em utilizar o prestígio e o saber reconhecido pela sociedade, aos profissionais, para possibilitar relações e experiências renovadas ${ }^{(18)}$, como forma de ampliar sua autonomia.

Esse tipo de intervenção tem grande importância para estes indivíduos, dessa forma acreditamos que o Escritório é um campo teórico-prático importante para o processo de formação dos profissionais da saúde, preocupado com a construção de um novo paradigma na atenção a saúde mental.

6. Aranha e Silva AL. Enfermagem em saúde mental: a ação e o trabalho de agentes de enfermagem no nível médio no campo psicossocial [tese]. São Paulo: Escola de Enfermagem, Universidade de São Paulo; 2003.

7. Aranha e Silva AL. 0 projeto a copiadora do CAPS: do trabalho de reproduzir coisas à produção de vida [dissertação]. São Paulo: Escola de Enfermagem, Universidade de São Paulo; 1998.

8. Gil AC. Como elaborar projetos de pesquisa. São Paulo: Atlas; 1991.

9. M inayo MCS, organizadora. Pesquisa social: teoria, método e criatividade. Petrópolis: Vozes; 1994.

10. Organização M undial da Saúde (OMS). Organização PanAmericana da Saúde (OPAS). Relatório Sobre a Saúde no M undo. Saúde mental: nova concepção, nova esperança. Genebra; 2001.

11. Kaplan HI, Sadock BJ, Grebb JA. Compêndio de psiquiatria. Porto Alegre: Artmed; 1997. 
12. Organização Mundial da Saúde (OMS). CID-10: Classificação Internacional das Doenças. São Paulo: Universidade de São Paulo; 1999.

13. Marsiglia R. Saúde mental e cidadania. São Paulo: Mandacaru; 1990.

14. Amarante $P$, organizador. Psiquiatria social e reforma psiquiátrica. Rio de Janeiro: FIOCRUZ; 1994.

15. Saraceno B. Libertando identidades: da reabilitação psicossocial a cidadania possível. Rio de Janeiro: Te Cora; 1999.
16. Castel R. As metamorfoses da questão social: uma crônica do salário. Petrópolis: Vozes; 1998.

17. Pitta AMF. Cuidando de psicóticos. In: Goldberg J. Clínica da psicose: um projeto na rede pública. Rio de Janeiro: Te Cora; 1996. p. 23-35

18. Kinoshita RT. Contratualidade e reabilitação psicossocial. In: Pitta A, organizadora. Reabilitação psicossocial no Brasil. 2a ed. São Paulo: Hucitec; 2001. p. 55-9. 